\title{
Perception of Non-Muslims towards Islamic Banking Revisited: SEM Approach
}

\section{Wan Ahmad Wan Omar}

\author{
Senior Lecturer, School of Business Innovation and Technopreneurship, Universiti Malaysia Perlis \\ Email: wanahmad@unimap.edu.my

\section{Hafizah Abdul Rahim}

Lecturer, School of Business Innovation and Technopreneurship, Universiti Malaysia Perlis Email: hafizahrahim@unimap.edu.m

\section{Doi:10.5901/mjss.2016.v7n1p139}

\begin{abstract}
This study investigates the relationships between non-Muslims' perceptions and acceptance towards Islamic banking in Malaysia. Specifically this research is to determine the significant contributing factors of perception and its measured indicators; and relationships between the factors which influence non-Muslims to accept Islamic banking. A total 250 respondents participated in the survey at selected areas in Kedah, Malaysia. A structural equation modelling (SEM) approach is employed for the study to provide a robustness to the perception and acceptance model which passes all validity and reliability tests to be a good fit model for causal hypotheses testing. Confirmatory factor analysis is utilised to test for model validity, reliability and goodness-of-fit of the model. The result of hypotheses has revealed that there is a significant relationship between perception among non-Muslims which is indicated by confidence and bank selection criteria, towards acceptance of Islamic banking system in Malaysia. Latent variable for perception also passes mediating test to be a significant mediator between the exogenous indicators and the endogenous acceptance towards Islamic banking.
\end{abstract}

Keywords: Non-Muslims' perception, Islamic banking, structural equation modelling (SEM), confirmatory factor analysis (CFA), Malaysia.

\section{Introduction}

Since the inception of Islamic banking and financial institution in the 1970s in a couple of Muslim majority countries, the studies on the perception and acceptance of their customers towards the system have been very active ${ }^{1}$. There are numerous reports on the study of perceptions of the non-Muslim Islamic banking patrons towards the acceptance of the products and services in various parts of the Muslim world including in non-Muslim countries (see Sudin Haron, et. al., (1994); Dar \& Presley, (1999); El-Nagar \& El-Biely, (2011); Noman Khan, et. al., (2007); and others). Albeit, significant result is reported in the previous studies but it lacks robustness in the modelling. The aim of this study is to reinvestigate the perception of non-Muslims towards Islamic Banking. The application of the structural equation modelling (SEM) in the studies of banking customers' perception among the non-Muslims is to overcome the lack of robustness in modelling. Malaysia has been chosen as a case study because of their commitment to the development of Islamic banking and financial services over the last three decades.

In 2011, the World Bank reported that there were more than 300 Islamic banking and financial services institutions in the world, operating in 75 countries including non-Muslim majority, with total asset value estimated between US\$1.0 to US $\$ 1.5$ trillion. The global Islamic financial industry has sustained its tremendous growth momentum in 2013 to reach an estimated US $\$ 1.8$ trillion in total assets value as at end of $2013^{2}$. The notion of Islamic banking refers to a banking

\footnotetext{
1 In 1969, the first International Conference on Islamic Economics was convened in Jeddah, Saudi Arabia which was attended by most of the prominent Islamic scholars around the world. One of the resolutions of the conference was to establish Islamic banking institution in members' countries. As a result, the first full fledge Islamic bank, Dubai Islamic Bank was incorporated in 1975, and followed by establishment of International Development bank in Jeddah, and some other private Islamic banks in Egypt, Malaysia, and other parts of the Muslim world. In August 1977, the International Association of Islamic Banks (IAIB) was set up as a technical advisory institution for Islamic banks.

2 Source: Insight - Islamic finance industry outperforms in 2013. Malaysia International Islamic Finance Centre (MIFC), retrieved on the June 14, 2015 at http://www.mifc.com/?ch=28\&pg=72\&ac=62\&bb=uploadpdf
} 
system or activity that is shari'ah (Islamic rulings) compliant, in which its practical application is based on the development of Islamic economics ${ }^{3}$. The principles of Islamic economics emphasise on moral and ethical values in all dealings and have to-date made a wide universal appeal especially in the banking and financial services. The basic principle of Islamic banking is founded on risk-sharing which is a component of trade rather than risk-transfer which is seen in conventional banking ${ }^{4}$. In its practical application, Islamic banking requires all financial transactions are to be supported by unpretentious productivity activity, to serve both Muslim and non-Muslim customers.

Perception refers to the state of mind in organising, identifying and interpreting the input information before a decision is made pertaining to the subject matter being brought up. In other words, perception involves the process of constructing mental representation of distal stimuli or object in the real world based on the available information that could be perceived. From psychological perspective, perceptions is shaped by the process of learning, memory, expectation and attention; which could be split into two processes, firstly by processing sensory input which transforms low-level information into higher level for object recognition; and secondly processing which is connected with the person's own concept and knowledge or expectations and selective mechanism that influence perception ${ }^{5}$. Hence, in this case of Islamic banking, the appeal of the banking products and services will enter into the first process of sensory input in providing the basic information on Islamic banking to provide customers' confidence. The bank selection criteria enters into the second process of expectation for perception and acceptance.

Structural equation modelling (SEM) is a multivariate statistical analysis technique that seeks to explain the relationships among the multiple variables, by examining the structure of interrelationships expressed in a series or multiple regression equations, which is called construct. One of the primary advantages of SEM is that it can be used to study the relationships among latent constructs that are indicated by multiple measures, and also applicable to both experimental and non-experimental data, as well as cross-sectional and longitudinal data (Hair, Black, Babin, \& Anderson, 2010). It takes a confirmatory (hypothesis testing) approach to the multivariate analysis of a structural theory, one that stipulates causal relations among multiple variables.

Hence, the objective of this study is to reinvestigate the relationships between perceptions and acceptance of Islamic banking system among the non-Muslims using structural equation modelling approach. This study will also determine the significant factors and its measurement indicators; as well as the mediating effect of perception as a mediator. This paper is structured into seven sections. Introduction on the study is discoursed in section one. Section two discusses literature review on the subject, and theoretical framework of the study in section three. Section four elaborates research methodology and data description related to the research. Findings from this research are presented in section five. Section six offers discussion on the findings and its policy implication, and section seven concludes the study.

\section{Literature Review}

Study on customers' perceptions on Islamic banking is relatively recent, in which the work of Erol \& El Bdour (1989) may be considered as one of the earliest studies in Islamic bank customers' perception based on the bank selection criteria that impact customers to patronise Islamic banking. They found that fast and efficient services, bank reputation, and confidentiality were the important factors in the bank selection criteria that determined customers' perception on accepting Islamic banking in Jordan. The other findings revealed that the peer group played crucial role in promoting Islamic banking, and religious motive was not important factor in bank selection criteria. A similar study has also been conducted by Sudin Haron, et. al., (1994) to determine the bank patronage factors among the Muslim and non-Muslim customers of Islamic banking in Malaysia. They found that both Muslims and non-Muslims perceived the same peculiarity in bank selection criteria. The Muslims consider fast and efficient service as the most important bank selection criteria but it ranks second among the non-Muslims. Friendliness of bank personnel is considered the most important factor by the non-Muslim customers. The ranking of other factors in bank selection criteria include speed of transaction, confidentiality, knowledge about the business of customer, and others (Haron, Ahmad, \& Planisek, 1994, p. 37).

The second causal factor of perception is appealing that makes the customers to patronise Islamic banking. Generally, the appealing of banking services and products include staff competency in handling banking matters, bank services reliability, convenience, and cost benefits (Athanassopoulos, Gounaris, \& Stathakopoulus, 2001). Study by Haque (2010) on attitudinal differences among Malaysian Islamic banking customers found that the banking system

\footnotetext{
3 Source: Islamic Banking, Institute of Islamic Banking and Insurance, retrieved on June 15, 2015 at http://islamic-banking.com.

${ }_{4}^{4}$ For detailed discussion on the concept and mechanic of Islamic banking, please refer to Mohamed Ariff, (1988), Islamic Banking in Southeast Asia. Cambridge, UK: Cambridge University Press.

${ }_{5}^{5}$ Please refer to Berstein, D.A., (2010), Essentials of Psychology, 5th Edition, Wadsworth Cengage Learning.
} 
possesses an appeal to attract customers by offering an integrated value added services and use of modern banking equipment. The other attributes in appeal are competitive profit rate and quality of services (see 'Ismah Osman, et al. (2009) and Norma Saad (2012)). The results of the previous studies on customers' satisfaction towards Islamic banking show that there is no attitudinal differences on the satisfaction among Muslim and non-Muslim customers based on the appeal of the bank.

Acceptance could also be measured by the confidence level of the banking services and products perceived by their customers. Previous findings from researchers on Islamic banking have outlined bank confidentiality, useful guidance by bank staff, trust level, transparency, transaction security, and the bank's good reputation and image as determinants of confidence (see Sudin Haron, et. al., (1994); Othman \& Owen, (2002); El-Nagar \& El-Biely, (2011); and others). Sudin Haron, et. al. (1994) have evaluated respondents' confidence level in selecting Islamic banking in terms of bank confidentiality with regards to their customer's account and transaction. He found that bank confidentiality was one of the most important factors among Muslim and non-Muslim customers to select Islamic banking. This result was also echoed by Naser, et. al. (1999) and Gerrard \& Cunningham (2001) in their respective studies among Muslim and nonMuslim customers' perception in Jordan and Singapore towards Islamic banking system. Credibility and honesty of banking staff is paramount in building confidence among the customers. Other than that, providing accurate and timely banking information is also essential among bank customers (Naser, et. al., 1999). No information should be disseminated to third party without customer's approval; otherwise it is considered a fraud. Transparency is another important point to increase confidence in Islamic banking. It also helps to lower panic level due to financial crises as observed by Akmal \& Saleem (2008) in which they have found that Islamic banking is sustainable because of transparency and practice in prevention of undue risk in the financial transaction.

Perception and acceptance of Islamic banking varies across demographic factors such as age, gender, education, income group, occupation, and others. Previous studies show that most of the Islamic banking customers comprises of younger generation with higher educational background (L00, 2010). Loo argues that age difference is an important factor in perception towards Islamic banking among non-Muslims in Malaysia, especially new generation where their perception is positive. In another study, Kaynak, et. al. (1991) suggested that other potential demographic factor influencing perception towards Islamic banking is educational background. They found that Islamic banking customers are generally from higher education group that understand the underpinning concept and Islamic banking's advantages. Finally, in the case of occupation, previous studies found that occupation has significant role in determining perception of Islamic banking customers, as observed by Boyd, et. al., (1994). This is because majority of white-collar employees focused on reputation and convenient facilities on banking selection, while the blue-collar group focused on the availability of basic banking services. The result from previous studies is a benchmark in formulating our theoretical research framework.

\section{Theoretical Framework}

The basic theoretical model constructs and hypotheses for this study is depicted in Figure 1, which shows the relationship between dependent latent variable, perceived acceptance of Islamic banking among non-Muslims (perceived acceptance), and independent latent variables on the appeal in Islamic banking products and services (appeal), bank selection criteria (selection criteria), and confidence in Islamic banking (confidence). The working definition of five constructs in the model include; (1) Acceptance is the reaction to patronising Islamic banking resulting from direct effect of the bank's appeal, selection criteria and confidence, or through mediating effect of perception; (2) Perception is a latent variable to reflect appealing, bank selection criteria and confidence, which is related to the level of acceptance; (3) Appeal is the extent of attractiveness in products and services; (4) Bank selection criteria is the criteria used by the respondents to select Islamic banking; and (5) Confidence is the level of belief towards Islamic banking. Perceived acceptance has also seven measured items, i.e. acceptance by non-Muslim, religion not an issue, concept of interest free and risk sharing, level of transparency, intend to patronise, competitiveness level, and acceptable to non-Muslim. 


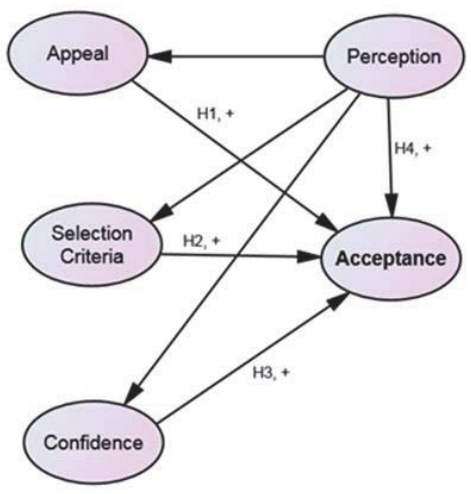

Figure 1. Theoretical model constructs and hypotheses

A new latent variable is also included into the model as a second order mediator for the three independent variables, in reflection to the dependent variable for mediating effect test. The hypotheses for the study include;

$\mathrm{H} 1$ : There is a positive relationship between the appeal of Islamic bank products and services to the acceptance;

$\mathrm{H} 2$ : Perceived acceptance is positively influenced by bank selection criteria;

H3: Confidence level of non-Muslims has positive effect on their perceived acceptance towards Islamic banking; and banking.

H4: Perception among non-Muslims has positive mediating effect to the perceived acceptance towards Islamic

\subsection{Methodology}

Structural equation modelling (SEM) is employed to seek the explanation of relationships between perceptions among non-Muslims towards acceptance of Islamic banking system in Malaysia. Following Hair, et al. (2010), the methodology involves estimating a series of separate, but interdependent, multiple regression equations by specifying structural model to be applied in a statistical package. First, we draw upon theory based on literature review, past experience, and the research objectives mentioned in previous section, to posit which independent variables predict each dependent variable. Dependent variables in one relationship may become independent variables in subsequent relationships, giving rise to the independent nature of the structural model. The proposed relationships are then transformed into a series of structural equations for each dependent variable, by inserting latent constructs or unobserved variables. A latent construct is a hypothesised concept that can be represented by a series of measureable items or indicators which is gathered through various data collection methods (such as surveys, tests, or observational methods). The advantages of deployment latent construct are two folds. First, we can better represent theoretical concepts to reduce measurement error. Second, it improves statistical estimation by accounting measurement error in the concept relationships.

The next step is to assess the proposed measurement model validity based on the results of two tests; (1) acceptable level of goodness-of-fit (GOF), and (2) existence of specific evidence of construct validity in the measurement model. The tools for GOF are the absolute, incremental and parsimony fit indices. Absolute fit indices measure of how well the model that we have specified reproduces the observed data. The test statistics include chi-square $\left(\chi^{2}\right)$ statistic, degrees of freedom (df), goodness-of-fit index (GFI), root mean square error of approximation (RMSEA), and ratio of chisquare $\left(\chi^{2}\right)$ to degree of freedom (df). Incremental fit indices differ from absolute fit indices in that it assess how well the estimated model fits relative to some alternative baseline model, or null model which assumes all observed variables are uncorrelated. These indices represent the improvement in fit by the specification of related multi-item constructs. The test statistics for incremental fit are normed fit index (NFI), Tucker-Lewis index (TLI), comparative fit index (CFI), and relative noncentrality index (RNI). Parsimony fit index is conceptually similar to an adjusted $\mathrm{R}^{2}$ value, in providing information which model is the best considering its fit relative to its complexity. The best known index for this fit is parsimony normed fit index (PNFI). Once the measurement model passes validity tests and produces a minimised recursive model, then we establish significant relationships between the constructs, and estimate the mediated model including assessment the level of mediation, in terms of total effects. This final stage will conclude the hypotheses testing. 


\subsection{Data Sampling and Instrument}

The location of the study is confined to the suburban areas in Kedah (situated north of Peninsular Malaysia) comprising the towns of Jitra, Sungai Petani, Kulim and Alor Setar, where the concentration of non-Muslims are higher. The population of the selected towns is fairly multiracial. As of 2010 census, non-Muslims in Kedah constitute $33.0 \%$ from total population of 1.8 million. Approximately 300 non-Muslim respondents have been randomly selected for the study, and each of them is provided with a set of questionnaire that contains measures of the model constructs concerning perceived acceptance of Islamic banking. The instruments for measuring the model constructs is based on 5 -facet Likert scale with items selection from previously developed instruments used by Sudin Haron, et. al., (1994), El-Nagar \& ElBiely, (2011), and other researchers.

The dependent variable construct on perceived acceptance towards Islamic banking is measured by 7 items or dimensions (DV1 to DV7) in the questions of non-Muslim acceptability, personality and religion, the interest of free concept, bank transparency, future banking, competitiveness, and compatibility. The first proposed independent latent variable is the appeal of Islamic banking products and services, which are also 7 -item dimension from A1 to A7 on reliability, pricing, range of products and services, service quality, better facilities and physical appearance, polite service, and sufficient information provided. The second independent latent variable is the confidence level towards Islamic banking which is also 7-item dimension ( $\mathrm{C} 1$ to $\mathrm{C} 7$ ), measuring level of confidentiality, reliable information, transparency, security assured, image and reputation, data privacy, and no fraudulent. The final independent latent variable, bank selection criteria (B1 to B7) measures convenience, number of ATM, cost and benefit of service, recommendation from peers, advertising effect, no religious restriction, and service efficiency.

\section{Research Findings}

\subsection{Respondents' Profile and Awareness of Islamic Banking}

Total completed questionnaires received are 250 sets or $83.3 \%$ of the total 300 sets distributed to the respondents in the selected areas. The respondents comprises of six age groups, in which about $80 \%$ are working group with age below 40 years, $61.2 \%$ female, $67.8 \%$ married; and the respondents are predominantly urbanites (66.8\%). The Islamic banking awareness among the respondents are relatively high, in which more than $64 \%$ of the respondents regardless of their income and occupation have adequate knowledge about Islamic banking system and are able to differentiate it from conventional banking.

\subsection{Descriptive Statistics}

The descriptive results in Table 1 indicate that the respondents perceive relatively higher mean score in all causal factors of perception - appeal, bank selection criteria and confidence, with mean score of 3.380 on 5-point Likert scale and relatively high standard deviation at 1.263 . The high standard deviation indicates that the respondent responses to the questions vary or deviates from the mean. Subsequently, the shape of responses from the respondents is well distributed around the mean score over the 5-facet Likert scale. The standard error of all the latent variables are relatively small, indicating reliability of the sample mean in reflecting the actual population mean. The mean score, standard deviation and standard error for dependent variable, acceptance level also reveals almost identical result. All latent variables have passed data reliability tests as indicated by higher than 0.7 critical value in Cronbach-a (Hair, et. al., 2010, p. 125). As all variables have passed data reliability test, we may proceed to convergent validity test for the constructs.

Table 1. Descriptive statistics and data reliability

\begin{tabular}{lccccc}
\hline Variable & Item & Mean & Std Dev & Std Error & Cronbach- $\boldsymbol{\alpha}$ \\
\hline Appeal (A) & 7 & 3.336 & 1.325 & 0.084 & 0.834 \\
Selection Criteria (B) & 7 & 3.416 & 1.228 & 0.078 & 0.819 \\
Confidence (C) & 7 & 3.388 & 1.237 & 0.073 & 0.818 \\
\hline Perception - mean & & 3.380 & 1.263 & 0.080 & 0.824 \\
Perceived Acceptance (DV) & 7 & 3.373 & 1.207 & 0.076 & 0.843 \\
Total Items & 28 & & & & \\
\hline
\end{tabular}




\subsection{Convergent Validity}

Convergent validity test is conducted based on confirmatory factor analysis (CFA) by deletion of measurement items with the highest modification index (MI) to meet the acceptable absolute and incremental fit indices with minimum SEM model achieved. Convergent validity test is to ensure that indicators of specific construct should converge or share a high proportion of variance in common, which may be estimated by factor loadings, average variance extracted (AVE), and construct reliability (CR). The good rule of thumb in convergent validity is that standardised loading estimates should be .5 or higher (ideally .7 or higher); AVE of .5 or higher; and CR between .6 and .7 is acceptable but .7 higher suggests good reliability (Hair, et. al., 2010, p. 709). High construct reliability indicates the existence of internal consistency in the model constructs.

The process of convergent validity test is performed by means of modification index (MI). The measureable variable or item with highest MI value will be first deleted and followed by the next consecutive highest MI until the acceptable level of fit indices are achieved, and the result is depicted in 2. The SEM model achieves acceptable standardised estimates in absolute and incremental fit indices (chi-square of 47.78, chi-square to df ratio of 1.6, RMSEA of .051, TLI of .971, and CFI of .981) after $64.2 \%$ deletion of measureable items comprising five items for latent variable appealing (A1 to A3, A5, A7), four items for bank selection criteria (B1, B3, B4, B5 and B7), four items for confidence (C1, $\mathrm{C} 3, \mathrm{C}$, and C7), and five items in dependent variable, perceived acceptance (DV1 to DV5). Factor loadings of all remaining measureable items in the SEM model pass .7 ideally cut-off point requirement (see Figure 2).

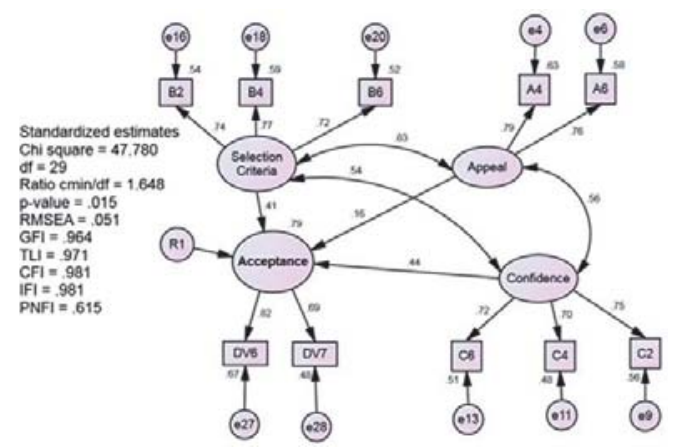

Figure 2. Path diagram for revised SEM model after convergent validity test

The results for average variance extracted (AVE) and constructive reliability (CR) from the revised SEM model are presented in Table 2, which indicate a good and acceptable convergent validity of the revised SEM model. The AVE estimate for each latent variable is higher than .5 acceptable level to be a good convergence. Two latent variables, appeal and dependent variable, acceptance have construct reliability (CR) readings between .6 to .7 to indicate good construct reliability, and the other two variables, bank selection criteria and confidence, both exceed .7 level. Hence, based on the retained items in the model at this point, there is adequate evidence that SEM model fits relatively well and convergent validity is provided. The next step is to test correlations result obtained from the new revised SEM model for nomological validity based on correlation matrix between the constructs, to ensure that the underpinning measurement theory of the model is a good fit to the stipulated theory.

Table 2. Result of convergent validity tests for revised SEM model

\begin{tabular}{lccccc}
\hline Variables & Items & Loading & Var Error & CR $^{6}$ & AVE7 $^{7}$ \\
\hline Selection Criteria & B2 & .74 & .54 & & \\
\hline
\end{tabular}

${ }^{6}$ Construct reliability $(C R)$ is calculated from the sum of squares of factor loadings $L_{i}$ for each construct and the sum of the error variance terms for a construct $e_{i}$ as follows: $C R=\frac{\left(\sum_{i=1}^{n} L_{i}\right)^{2}}{\left(\sum_{i=1}^{n} L_{i}\right)^{2}+\left(\sum_{i=1}^{n} e_{i}\right)}$

${ }^{7}$ Average variance extracted (AVE) is calculated from sum of the standardised factor loading for each item, $L_{i}$ and number of items, $n$ as follows: $A V E=\frac{\sum_{i=1}^{n} L_{i}^{2}}{n}$ 


\begin{tabular}{lccccc}
\hline Variables & Items & Loading & Var Error & CR $^{6}$ & AVE7 $^{7}$ \\
\hline \multirow{4}{*}{ Appeal } & $\mathrm{B} 4$ & .77 & .59 & & \\
& $\mathrm{~B} 6$ & .72 & .52 & .751 & .518 \\
Confidence & $\mathrm{A} 4$ & .79 & .63 & & \\
& $\mathrm{~A} 6$ & .76 & .58 & & \\
& $\mathrm{C} 2$ & .75 & .56 & & .601 \\
Acceptance & $\mathrm{C} 4$ & .70 & .48 & & \\
& $\mathrm{C} 6$ & .72 & .51 & .752 & .524 \\
& & & & \\
Note: CR = construct reliability; AVE = average variance extracted & .574 \\
\hline
\end{tabular}

\subsection{Nomological Validity}

Correlation between the constructs for revised SEM model is shown in Table 3, which revealed that these constructs are significantly positive related to one another at .01 significant level or less. Specifically, bank selection criteria and confidence both have significant positive correlation with the perceived acceptance. However, only one correlation is inconsistent with this prediction. The correlation estimate between appeal and acceptance is positive but not significant ( $p$ $=.296)$. Considering the other two constructs are consistent, this one exception is not a major concern.

Table 3. Revised SEM model construct correlation matrix (standardised)

\begin{tabular}{lcccc}
\hline & Appeal & Criteria & Confidence & Acceptance \\
\hline Appeal & 1 & .684 & .318 & .027 \\
Criteria & $.827^{\star * *}$ & 1 & .296 & .171 \\
Confidence & $.564^{\star * *}$ & $.544^{\star * *}$ & 1 & .197 \\
Acceptance & .163 & $.414^{\star *}$ & $.444^{* * *}$ & 1 \\
\hline Significance level: ${ }^{*}=.05,{ }^{* *}=.01,{ }^{* * *}=.001$ & & \\
Note: Values below the diagonal are correlational estimates between constructs, diagonal elements are construct \\
variances, and values above diagonal are squared correlations.
\end{tabular}

Previous research findings suggest that appealing, bank selection criteria and confidence are the causal factors of perception (see Erol \& El Bdour (1989), Haque (2010), and Sudin Haron, et al. (1994)). Hence, a new construct for perception is necessary to depict the key relationships in the theoretical framework is being studied, namely the relationship between perception of non-Muslims towards acceptance of Islamic banking. This measure is considered helpful to enhance nomological validity.

\subsection{Goodness-of-Fit of SEM Model}

After the revised measurement SEM model has been specified and passed all required reliability and validity tests, we now come to the critical decision whether the model is really a valid model. The GOF is the decision to see the revised measurement model fits into the variance-covariance matrix of the dataset. The result of GOF tests for the revised SEM model is presented in Table 4.

Table 4. Comparison of goodness-of-fit measures between initial and revised model

\begin{tabular}{|c|c|c|c|c|c|c|c|}
\hline & Appeal (A) & Criteria (B) & Confidence (C) & Ind $\operatorname{Var}(\mathrm{A}, \mathrm{B}, \mathrm{C})$ & Accept (DV) & Initial Model & Revised Model \\
\hline $\begin{array}{l}\text { Items remain } \\
\text { Absolute Fit Indices }\end{array}$ & 7 & 7 & 7 & 21 & 7 & 28 & 10 \\
\hline Chi-square $\left(\chi^{2}\right)$ & 310.83 & 149.06 & 140.27 & 1126.49 & 86.20 & 1459.84 & 47.78 \\
\hline df & 14 & 14 & 14 & 186 & 14 & 344 & 29 \\
\hline$\chi^{2} / \mathrm{df}$ ratio & 22.2 & 10.6 & 10.0 & 6.1 & 6.1 & 4.2 & 1.6 \\
\hline p-value & .00 & .00 & .00 & .00 & .00 & .00 & .015 \\
\hline GFI & .722 & .830 & .844 & .554 & .902 & .579 & .964 \\
\hline
\end{tabular}




\begin{tabular}{|c|c|c|c|c|c|c|}
\hline $\begin{array}{l}\text { RMSEA } \\
\text { Incremental Fit Indices }\end{array}$ & .292 & .197 & .190 & .143 & .144 & .114 \\
\hline $\mathrm{CFI}$ & .659 & .772 & .790 & .682 & .883 & .722 \\
\hline $\begin{array}{l}\text { TLI } \\
\text { Parsimony Measure }\end{array}$ & .489 & .657 & .686 & .641 & .825 & .684 \\
\hline PNFI & .662 & .504 & .517 & .571 & .577 & .607 \\
\hline
\end{tabular}

Notes: Ind Var = independent variables; DV = dependent variable. $\mathrm{df}=$ degree of freedom; GFI = goodness-of-fit index; RMSEA = root mean square error of approximation; CFI = comparative fit index; TLI = Tucker Lewis index; PNFI = parsimony normed fit index.

The revised model has achieved local minimisation and recursive but the measureable items remained is down to 10 as compared to 28 items in the initial model, or more than 60\% reduction. All CFA constructs in the revised model surpass the cut-off points to be a good fit model. The overall model chi-square is 47.48 with 29 degree of freedom and $p$-value associated with this result is .015 which is significant at .05 based on type I error rate. Hence, the chi-square goodnessof-fit indicates that there is a difference between the hypothesised model and measurement model within sample data. Chi-square ratio to degree of freedom at 1.6 times is less than 2 times, GFI of .964 and RMSEA of .051 of absolute fit indices show that the revised model is structural fit the sample data. CFI and TLI results at .981 and .971 respectively, all above .9 cut-off point, indicating the estimated model fits well relative to the incremental fit indices. At this point, revised SEM model of perception has significantly improved its original structural model, and the results show reasonably good overall fit and the hypothesised relationships are generally supported.

\subsection{Mediating Effect Analysis of Revised Model}

The mediating effect of latent variable, perception as a mediator is tested on second order path diagram of the new revised model as depicted in Figure 3. The model passes all goodness-of-fit tests with regards to absolute fit (chi-square of 26.752, ratio chi-square to df of 1.16, RMSEA of .026), incremental fit (TLI of .994, CFI of .996, IFI of .996), and parsimony fit (PNFI of .623). Therefore, perception is confirmed as mediator in reflecting the latent variables of bank selection criteria, the appeal of bank products and services, and confidence in bank, in relation to the dependent variable of acceptance.

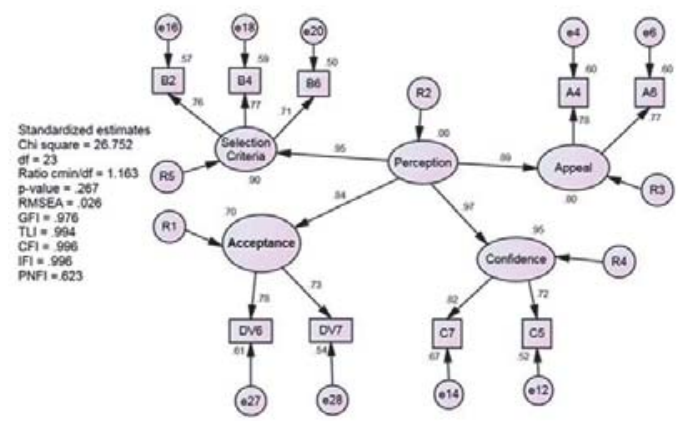

Figure 3. The mediating effect of perception as a mediator on acceptance

The position of perception as a significant mediator is confirmed with the result of comparison between direct and indirect effect of mediator in Table 5. The result shows that indirect effect of perception to dependent variable acceptance in all relationships are less than direct effect. The highest total effect is 1.27 for perception to confidence to acceptance relationship, suggesting that level of confidence is the major factor for perception to acceptance in Islamic banking among non-Muslims.

Table 5. Total effect on perception as mediator

\begin{tabular}{lccc}
\hline Relation & Direct Effect & Indirect Effect & Total Effect \\
\hline Perception $\rightarrow$ Criteria $\rightarrow$ Acceptance & .84 & $.85 \times .41=.35$ & 1.19 \\
Perception $\rightarrow$ Confidence $\rightarrow$ Acceptance & .84 & $.97 \times .44=.43$ & 1.27 \\
Perception $\rightarrow$ Appeal $\rightarrow$ Acceptance & .84 & $.89 \times .16=.14$ & 0.98 \\
\hline
\end{tabular}




\subsection{Hypotheses Results}

The result of hypotheses testing based on revised model is presented in Table 6. Latent variable appeal in the prediction of acceptance is not significantly different from zero at .05 level (two-tailed), so we reject this hypothesis. The bank selection criteria in the prediction of acceptance is significantly different from zero at the .01 level (two-tailed), while confidence is significantly different from zero at .001 level (two-tailed). The mediator variable, perception in the prediction of acceptance is also highly different from zero at .001 level (two-tailed). The test of outlier in the model using Mahalanobis distance or $D^{2}$ over degree of freedom revealed that $t$-value is 1.115 which is less than 2.5 cut-off point for multivariate outlier, suggesting the model possess statistical properties that allow for significance test. Generally, hypotheses results suggest that perception as indicated by bank selection criteria and confidence has significant means large enough to be noticed or have an effect, highly important positive impact on the acceptance of Islamic banking among non-Muslims in Malaysia.

The bank selection criteria are measured by three out of seven items as in the initial construct. The significant measureable items for bank selection criteria include availability of automated teller machine, peers' recommendation to select Islamic banking, and efficient services rendered by the Islamic banking staff. Transparency in bank account and operation, image and reputation, and trust are the major measurement indicators for latent variable confidence level. While the remaining measured items for dependent variable, acceptance comprise of higher competitiveness, and banking products and services are for all regardless of religion.

Table 6. Hypotheses testing results conducted on revised model

\begin{tabular}{|c|c|c|c|c|c|c|c|}
\hline $\mathrm{H}$ & Dep Var & & Ind Var & Std Est & S.E & $p$-value & Result \\
\hline $\mathrm{H} 1$ & Acceptance & $\leftarrow$ & Criteria & .414 & .138 & .007 & Assert \\
\hline $\mathrm{H} 2$ & Acceptance & $\leftarrow$ & Appeal & 163 & .118 & .296 & Reject \\
\hline H3 & Acceptance & $\leftarrow$ & Confidence & .444 & .082 & .000 & Assert \\
\hline $\mathrm{H} 4$ & Acceptance & & Perception* & .801 & .095 & .000 & Assert \\
\hline
\end{tabular}

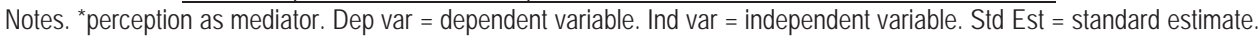

S.E = standard error.

The result of regression weights between the constructs is presented in Figure 5, which reveals a significant relationships between second order latent variable perception as a mediator to other latent independent variables; appeal, bank selection criteria and confidence to the dependent variable perceived acceptance $(\beta=.835, \mathrm{~S} . \mathrm{E}=.085, p$-value $=.000)$. Furthermore, this result is basically confirmed that the SEM model has empirically explained the relationships between perception and non-acceptance among non-Muslims towards Islamic banking based on its underpinning theory.

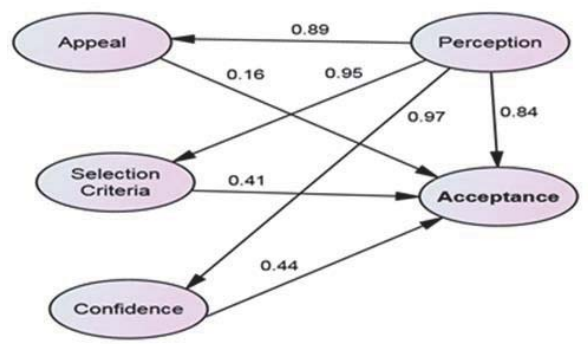

Figure 5. Regression weight between constructs of perception as a mediator

\section{Discussion and Policy Implication}

This research has investigated the relationships between perceptions of non-Muslims towards acceptance for Islamic banking in Malaysia. The model is conceptualised based on the works of Athanassopoulos, et al. (2001), Sudin Haron, et al. (1994) and Erol \& El Bdour (1989). The application of structural equation modelling provides robustness in the regression between variables, to circumvent some limitations of traditional multiple regression methods, includes fulfilling 
the underlying assumptions on data normality, linearity, constant variance of the error terms (homoscedasticity) and its interdependency (Hair, Black, Babin, \& Anderson, 2010, p. 182). SEM approach uses maximum likelihood (ML) method to estimate the relationships between variables and hypotheses testing. The initial hypothesised model for the study as expected, did not pass goodness-of-fit tests in the first run. The implication is that initial hypothesised model could not be generalised to the population, as data sample was only collected from a small selected area. The model has been revised and eventually passed goodness-of-fit tests in terms of absolute, incremental and parsimony fits, indicating that a credible relationship existed between perception and Islamic banking acceptance constructs.

There is a plausible difference between the testing results of initial hypothesised and the final revised models. The difference is expected as several tests have been performed on initial hypothesised model to ensure internal consistency in the model constructs and the relationship is not spurious but supported by theoretical framework before hypotheses could be concluded. As a result, more than $60 \%$ of observed items have been removed from the latent variables in order to achieve the target goodness-of-fit as a good model to explain the relationship between perception and acceptance of Islamic banking among non-Muslims. Significant improvement in GOF is recorded in the chi-square from 1495.8 in the initial model to 47.8 in the revised model or $96.8 \%$ reduction, chi-square to degree of freedom from 4.2 to 1.6 times (61.9\% reduction) and RMSEA from .114 to .051 (55\% improved). Similar improvements are also recorded in other goodness-of-fit tests; to indicate that the model is robust for hypotheses testing.

There is a significant positive impact of appeal to acceptance of Islamic banking among non-Muslims in Malaysia. The significant observed variables for appeal are the belief that the bank staffs provide comfortable and effective services, and they treat their customers politely. The other five observed items are deleted during confirmatory factor analysis process. On the bank selection criteria, the remaining three significant observed items include availability of ATM, peers' recommendation, and no religious barrier. This finding is consistent with the results of other researchers but different in terms of measured or observed items. Erol \& El Bdour (1989) found that fast and efficient services, bank reputation and confidentiality were the major indicators for bank selection criteria, while Sudin Haron, et al., (1994) added staff friendliness, speed and knowledgeable staff as additional major indicators for bank selection criteria. The significant observed items for confidence are the belief that the bank provides exact information to their customers, customers' confidence with the banking security system, and the bank will not reveal their customer's privacy to third party without consent. This study also found that perception is significantly reflected by appealing, bank selection criteria, and confidence. However, appeal has failed in the hypothesis testing as a factor of perception. The remaining measured items for dependant variable acceptance are level of competitiveness, and level of bank acceptance by all.

The result from this study provides marketing strategies to allure the non-Muslim customers to patronise Islamic banking services in selecting the right approaches for bank selection criteria and confidence level. Adopting the right strategy and approach will attract more customers from the non-Muslims group to Islamic banking.

\section{Conclusion}

The study employs structural equation modelling to investigate the relationships between perception and acceptance of Islamic banking among non-Muslim customers in Malaysia, using confirmatory factor analysis method in realising a goodness-of-fit and robust model for hypotheses testing.

The final revised model has passed goodness-of-fit tests as a robust and credible model construct, in which all four hypotheses except one are asserted or confirmed. The rejected one, appeal is not a significant factor in perception. Hence, the perception which is reflected by selection criteria and confidence has a significant impact of the acceptance among non-Muslims towards Islamic banking. In mediating effect analysis, perception is confirmed as a significant mediator to selection criteria, appeal and confidence to influence the acceptance of Islamic banking. Therefore, the final revised structural equation model has empirical explained that perception plays an important role among non-Muslims whether to accept or to reject Islamic banking based on sampling data collected in selected areas in Kedah, Malaysia.

The findings suggest that Islamic banking institutions need to refocus marketing strategy in alluring non-Muslims towards patronising Islamic banking because their perception are based on selection criteria and confidence as causal factors in acceptance of Islamic banking system but not on the appeal of the bank.

\section{References}

Akmal, M., \& Saleem, M. (2008). Technical efficiency of the banking sector in Pakistan. SBP Bulletin, 4(1), 61-80.

Athanassopoulos, A., Gounaris, S., \& Stathakopoulus, V. (2001). Behavioral responses to customer satisfaction: An empirical study. European Journal of Marketing, 35(5), 687-707. 
Boyd, W., Leonard, M., \& White, C. (1994). Customer preferences for financial services: an analysis. International of Bank Marketing, 12(1), 9-15.

Dar, A., \& Presley, J. (1999). Islamic finance: a Western perspective. International Journal of Islamic Financial Services, 1(1).

El-Nagar, H., \& El-Biely, M. (2011). A comparison of banking behavior of Islamic bank customers: some evidence for Egypt and Kingdom of Saudi Arabia. International Journal of Economics and Financial Studies, 1(1), 1-14.

Erol, C., \& El Bdour, R. (1989). Attitude, behavior and patronage factors of bank customers towards Islamic banks. International Journal of Bank Marketing, 7(6), 31-37.

Gerrard, P., \& Cunningham, B. (2001). Singapore's undergraduates: how they choose which bank to patronize. International Journal of Marketing, 19(3), 104-114.

Hair, J. F., Black, W. C., Babin, B. J., \& Anderson, R. E. (2010). Multivariate data analysis: a global perspective, 7th Edition. Singapore: Pearson Prentice Hall.

Haque, A. (2010). Islamic banking in Malaysia: a study of attitudinal differences of Malaysian customers. European Journal of Economics , Finance and Administrative Science(18), 7-18.

Haron, S., Ahmad, N., \& Planisek, S. (1994). Bank patronage factors of Muslims and non-Muslims customers. International Journal of bank Marketing, 12(1), 32 - 40.

'Ismah Osman, Huniyati Ali, Anizah Z, Wan Edura, W., \& Kamaruddin, J. (2009). Customers satisfaction in Malaysian Islamic banking. International Journal of Economics and Finance, 1(1), 197-202.

Kaynak, E., Kucukemoroglu, O., \& Odabasi, Y. (1991). Commercial bank selection in Turkey. International Journal of Bank Marketing, $9(4), 30-45$.

Loo, M. (2010). Attitudes and perceptions towards Islamic banking among muslims and non-muslims in Malaysia: implications for marketing to babyboomer and X-generation. International Journal of Arts and Sciences, 3(13), 453-485.

Naser, K., Ahmad, J., \& Al Khatib, L. (1999). Islamic banking: a study of customer satisfaction and preferences in Jordan. International Journal of Banking Marketing, 17(3), 135-150.

Noman Khan, M., Kabir Hassan, M., \& Ibneyy Shahid, A. (2007). Banking behavior of Islamic bank customers in Bangladesh. Journal of Islamic Economic, Banking and Finance, 3(2), 159-194.

Norma Saad. (2012). Comparative analysis of customer satisfaction on Islamic and conventional banks in Malaysia. Asian Social Science, 8(1), 73-80. doi:10.5539/ass.v8n1p73

Othman, A., \& Owen, L. (2002). The multi-dimensionality of CATER model to measure customer service quality in Islamic banking industry: a study of Kuwait Finance House. International Journal of Islamic Financial Services, 3(4), 6-12. 